SCIENTIFIC REPORT

\title{
Unregistered visual impairment: is registration a failing system?
}

\section{R J Barry, P I Murray}

Br J Ophthalmol 2005;89:995-998. doi: 10.1136/bjo.2004.059915

Background/aims: To assess the current level of underregistration of blindness and partial sight among patients attending a large teaching hospital, and to determine any risk factors for under-registration.

Methods: Medical records of all patients attending general ophthalmology outpatient clinics over a 3 month period were included in a retrospective analysis of registration rates; questionnaire survey assessing the level of knowledge of registration practices among 35 ophthalmologists working in the West Midlands.

Results: 146/2161 (7\%) patients were eligible for blind or partial sight registration, or were in possession of a completed BD8 form. Of these 146 patients, $65(45 \%)$ were unregistered with 18 fulfilling the criteria for blind and 47 for partially sight. In addition, 32/81 (40\%) registered patients appeared to have been inappropriately registered. Partially sighted patients were more likely to be unregistered than blind patients (OR 2.31, 95\% Cl 1.15 to $4.63, \mathrm{p}=0187$ ), and patients from ethnic minorities were more than three times more likely to be unregistered than white patients (OR $3.23,95 \% \mathrm{Cl} 1.56$ to $6.65, p=0.0015)$. A patient with a treatable condition was more likely to be unregistered than a patient with an untreatable condition (OR $4.87,95 \% \mathrm{Cl} 2.10$ to 11.33, $p=0.0002$ ). The overall level of knowledge of registration practices among doctors was found to be low and there was no indication of increasing knowledge with increasing experience.

Conclusions: There has been little improvement in registration rates of visually impaired patients over the past decade. Ophthalmologists lack the necessary knowledge to cater for visually impaired patients' needs.

$\mathrm{T}$ he latest estimates from the Royal National Institute for the Blind (RNIB) suggest that there are as many as 260000 unregistered blind, and 500000 unregistered partially sighted (PS) people living in the United Kingdom. ${ }^{1}$ Ophthalmologists have long been aware that a substantial proportion of those eligible for registration remains unregistered, ${ }^{2-5}$ with approximately $53 \%$ of eligible patients not been registered despite consultation with an ophthalmologist. ${ }^{3-5}$ Studies from the United States have shown that underregistration may be exacerbated by a lack of knowledge among eyecare providers themselves, with registration rates proportional to the experience of the examining doctor. ${ }^{67}$

In response to these findings, we decided to undertake a study with two broad aims:

(1) To update the most recent under-registration statistics collected in 1994, and assess whether there has been any improvement in the UK registration system.
(2) To assess the level of awareness of registration in doctors practising ophthalmology in the United Kingdom.

\section{METHODS}

Research was undertaken at the Birmingham and Midland Eye Centre (BMEC), a large single specialty hospital in west Birmingham. The West Birmingham local research ethics committee granted ethical approval for the study.

\section{Under-registration study}

Medical records of all patients attending general ophthalmology outpatient clinics at BMEC between October and December 2003 were scrutinised in a retrospective analysis of registration rates. General clinics were selected as analysis of special interest clinics may give a biased impression of the level of blind and PS registration. These months were chosen as plots of the distribution of blind and PS registrations by month between 1999-2003 revealed little between month variability (data not shown).

Patients previously registered as blind or PS, or who met the Department of Health (DoH) eligibility criteria for blind or PS registration as printed on the BD8 certificate on the day of their most recent clinic attendance in the study period were included.

A further group of patients (previously highlighted by Robinson $e a^{3}$ ) were included if they met the World Health Organization (WHO) criteria for PS as used in the RNIB needs survey, ${ }^{1}$ and had a visual acuity of 6/24 Snellen to 6/36 Snellen but no visual field defect, opacities in media, or aphakia. This group of patients is not included in BD8 guidelines for PS registration, and these patients were listed separately as the "6/24-6/36 group."

\section{Ophthalmologists' awareness study}

A questionnaire was constructed for the purpose of a pilot study to assess the level of knowledge of registration practices among doctors practising in the West Midlands, and in particular to investigate the relation between grade and experience with the level of knowledge. The questionnaire was aimed at answering whether these doctors

(1) have a detailed knowledge of who should and should not be registered? (based on the DoH guidelines as printed on the BD8 form, and as further defined by Bunce et $a l^{4}$ )

(2) have a detailed knowledge of the benefits of registration to a visually impaired individual, as indicated by the DoH? ${ }^{8}$

Abbreviations: BMEC, Birmingham and Midland Eye Centre; BST, basic specialist training; DoH, Department of Health; HST, higher specialist training; PS, partially sighted; RNIB, Royal National Institute for the Blind 
Table 1 Study sample demographics

\begin{tabular}{|c|c|c|c|c|c|}
\hline \multirow[b]{3}{*}{ Study factor } & & \multicolumn{4}{|c|}{ Category of impairment } \\
\hline & & \multicolumn{2}{|l|}{ Blind } & \multicolumn{2}{|c|}{ Partial sight } \\
\hline & & No & $\%$ & No & $\%$ \\
\hline \multirow[t]{2}{*}{ Sex } & Male & 30 & 21 & 40 & 27 \\
\hline & Female & 26 & 18 & 50 & 34 \\
\hline \multirow[t]{5}{*}{ Age } & $18-49$ & 10 & 7 & 9 & 6 \\
\hline & $50-64$ & 7 & 5 & 11 & 8 \\
\hline & $65-74$ & 5 & 3 & 11 & 8 \\
\hline & $75+$ & 34 & 23 & 59 & 40 \\
\hline & Median (range) & $77(21-98)$ & & & \\
\hline \multirow[t]{5}{*}{ Ethnicity* } & White & 35 & 24 & 64 & 44 \\
\hline & Asian & 16 & 11 & 19 & 13 \\
\hline & Black & 4 & 3 & 6 & 4 \\
\hline & Other & 1 & 1 & 0 & 0 \\
\hline & Unknown & 0 & 0 & 1 & 1 \\
\hline Grade of examining & Consultant & 18 & 12 & 28 & 19 \\
\hline \multirow[t]{5}{*}{ doctor } & Fellow & 8 & 5 & 13 & 9 \\
\hline & SpR & 9 & 6 & 15 & 10 \\
\hline & $\mathrm{SHO}$ & 4 & 3 & 15 & 10 \\
\hline & NTG & 10 & 7 & 17 & 12 \\
\hline & Data unavailable & 7 & 5 & 2 & 1 \\
\hline
\end{tabular}

(3) offer any other services to visually impaired patients at the point of registration? (based on the findings of Greenblatt $^{7}$ ).

Questionnaires were scored out of a total of 35, and distributed to all grades of ophthalmologist attending the weekly regional postgraduate teaching programme. This gave no opportunity to look up answers, and little chance to confer.

\section{Data analysis}

All data were entered into a Microsoft Excel spreadsheet, then analysed on a PC using the logistic regression function of StatsDirect.

\section{RESULTS}

A total of 2161 patients attended general ophthalmology clinics at BMEC between October and December 2003; 146 (7\%) patients met DoH eligibility criteria for blind or PS registration, or were in possession of a completed BD8 form (table 1).

Of these 146 patients, 56 (38\%) were registered as (38/56), or were eligible $(18 / 56)$ to be certified blind. Ninety patients $(62 \%)$ were registered as $(43 / 90)$, or were eligible $(47 / 90)$ to be certified PS. Overall, 65/146 (45\%) eligible patients were found to be unregistered. Of these 65,18 fulfilled the criteria for blind and 47 for PS registration (fig 1).

In addition, 32/81 (40\%) registered patients appeared inappropriately registered; $13 / 38(34 \%)$ of those registered as blind and 19/43 (44\%) of those registered PS were not certified in accordance with their level of visual impairment (fig 1).

There were 34 patients identified as meeting WHO criteria for PS, but did not meet BD8 guidelines and were therefore unregisterable ("6/24-6/36 group").

Glaucoma was the commonest cause of visual impairment, followed by ARMD, with cataract and retinitis pigmentosa joint third (fig 2).

At least $80 \%$ of patients with a primary diagnosis of cataract, corneal pathology or unexplained causes were found to be unregistered. All patients with aphakia, congenital blindness, optic atrophy, and retinitis pigmentosa were registered (fig 2).

Unregistered patients had been, on average, eligible for 1 year (range 0-12 years) and made an average of four visits (range 1-54) to BMEC by the end of the study period (table 2).

Table 3 shows PS patients were more likely to be unregistered than blind patients, and patients from ethnic minority groups (Asian, black, mixed, or other) were shown to be more than three times more likely to be unregistered than White patients. A patient who made a total of four or fewer visits to BMEC was more likely to be unregistered than a patient making five or more visits, and a patient with a treatable condition was more likely to be unregistered than a patient with an untreatable condition. There was a statistically significant association between registration status and presence of a reversible diagnosis. Patients aged 65 or over were more likely to be inappropriately registered than those under the age of 65. No association was found between

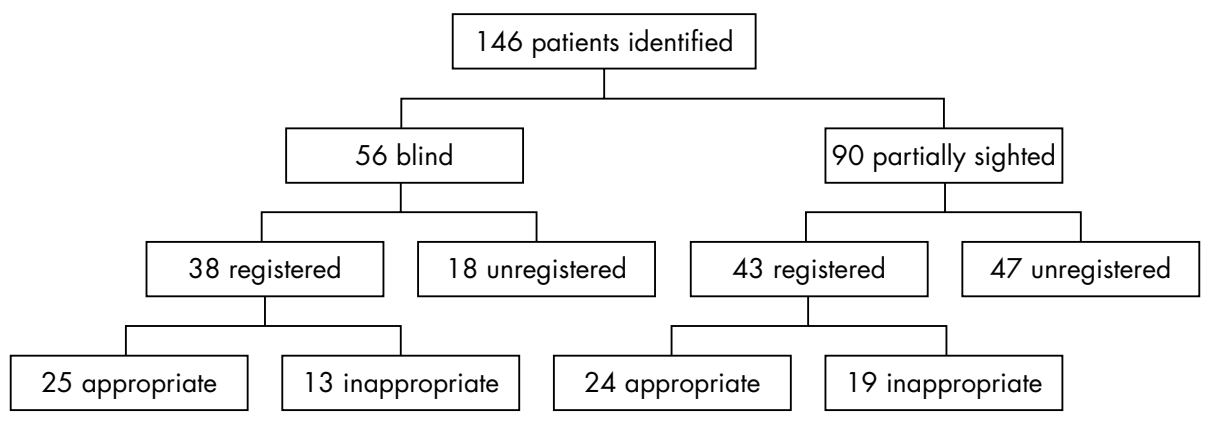

Figure 1 Flow diagram to illustrate the blind/partial sight breakdown of the study sample. 


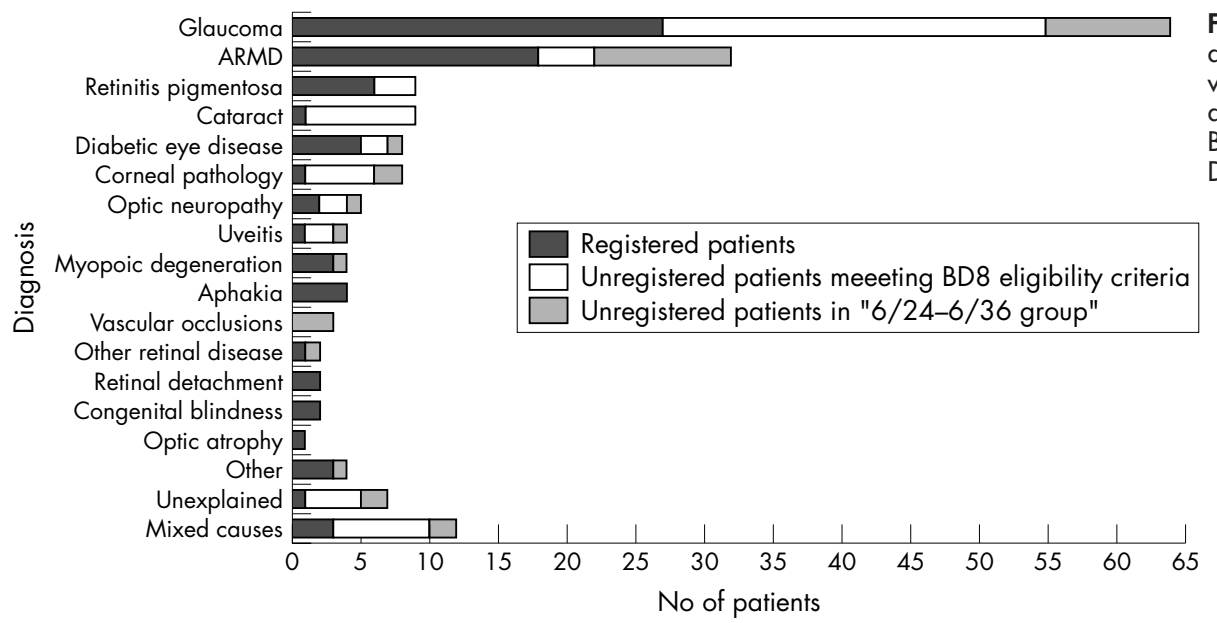

Figure 2 Primary ophthalmic diagnosis and registration status of visually impaired patients in attendance at general ophthalmology clinics at $B M E C$ for the period October to December 2003.

Registered patients

Unregistered patients meeeting BD8 eligibility criteria

No of patients

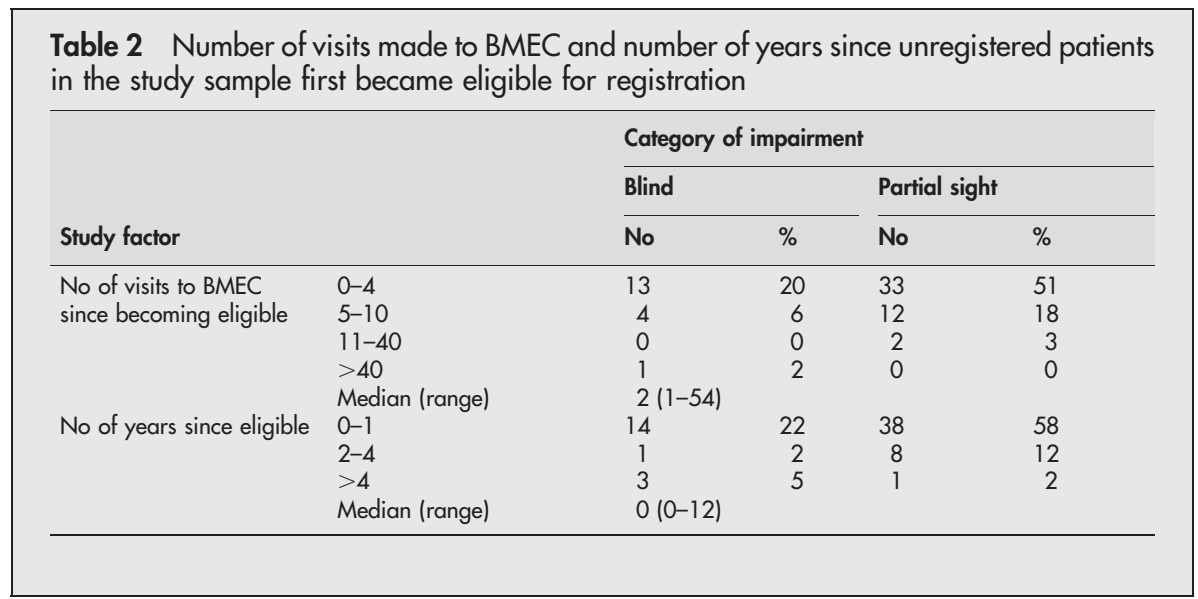

Table 3 Logistic regression analysis showing statistically significant variables

\begin{tabular}{llll}
\hline Variable & Odds ratio & $95 \% \mathrm{Cl}$ & $\mathbf{p ~ V a l u e ~}$ \\
\hline PS $v$ blind unregistered & 2.31 & 1.15 to 4.63 & 0.0187 \\
Ethnic minority $v$ white unregistered & 3.23 & 1.56 to 6.65 & 0.0015 \\
$\leqslant 4 v \geqslant 5$ visits unregistered & 2.51 & 1.06 to 5.96 & 0.0362 \\
$\begin{array}{l}\text { Treatable } v \text { untreatable } \\
\text { condition unregistered }\end{array}$ & 4.87 & 2.10 to 11.33 & 0.0002 \\
$\begin{array}{l}\text { Registration status and presence } \\
\text { of reversible diagnosis }\end{array}$ & 3.75 & 1.32 to 10.63 & 0.0128 \\
$\begin{array}{l}>65 \text { years } v<65 \text { years } \\
\text { inappropriately registered }\end{array}$ & 3.14 & 1.03 to 9.58 & 0.045 \\
\hline
\end{tabular}

registration status and the grade of the examining doctor ( $\mathrm{p}>0.9$; OR not calculated).

The questionnaire study revealed doctors demonstrated an overall low level of knowledge (less than 50\% awareness). There was no increase in awareness with increasing years experience or advancing grade (table 4).

\section{DISCUSSION}

Using DH eligibility criteria, we identified 65 patients who were unregistered and therefore receiving an inadequate level of support for their visual impairment. On average, these patients had been excluded from the blind and PS registers at four separate consultations over a l year period. Nevertheless, there may be limitations with generalisation of these findings, as the study was undertaken at a single inner city unit.

This study has again highlighted an unregisterable group of patients, the "6/24-6/36 group," who were visually impaired under the WHO classification of PS, but not under DoH guidelines. These patients are undoubtedly visually impaired and deserve the benefits offered by registration, but cannot legally be registered.

A PS person was almost 2.5 times more likely to be unregistered than a blind patient, which is broadly similar to that quoted by Bunce et $a l_{,}{ }^{4}$ and this trend mirrors previous studies. ${ }^{2-5}{ }^{10}$ Furthermore, this suggests little has changed since the work of Gibson et $a l^{2}$ in the 1980s. Owing to the retrospective nature of this investigation, we were unable to 
Table 4 Questionnaire scores stratified by grade of doctor

\begin{tabular}{lcl}
\hline Grade & Number polled & Average total score out of $35(95 \% \mathrm{Cl})$ \\
\hline Consultant & 6 & $17.1(13.6$ to 20.5$)$ \\
SpR & 15 & $15.9(14.2$ to 17.6$)$ \\
SHO & 9 & $16.1(13.8$ to 18.3$)$ \\
Non-training & 5 & $14.9(12.0$ to 17.8$)$ \\
\hline
\end{tabular}

confirm whether each patient had been offered registration or not. However, apart from one patient in the "6/24-6/36 group" there was no documentation in the medical records to suggest that any other patients had declined the chance of registration if it was offered.

In agreement with Robinson et al. ${ }^{3}$ another significant risk factor of under-registration identified was patient ethnicity. A patient who is "non-white" is more than three times more likely to be unregistered than a patient from a "white" ethnic group. One possible explanation is that there may be communication difficulties during the consultation between a member of an ethnic minority group and a doctor. It has been suggested that this leads to a reduced awareness of health information resulting in the patient not understanding the need for registration. ${ }^{11}$ Another explanation may be that patients in ethnic minority groups have more inhibitions to being registered than those from a white background, particularly in the case of elderly patients. ${ }^{12}$

Our results also suggest that patients with a treatable ophthalmic diagnosis are less likely to be registered than those with an untreatable condition. This confirms the findings of previous researchers, ${ }^{4}$ and adds further weight to the view expressed by King et al that registration is seen by ophthalmologists to be a last resort in the treatment of a visually impaired patient. ${ }^{5}$ A similar association was found when comparing patients with potentially reversible diagnoses with those with irreversible diagnoses.

Another finding was that under-registration was not associated with the grade of the examining doctor, suggesting possible inadequacies in the training of ophthalmologists. Further evidence for this came from the questionnaire study revealing the doctors' poor awareness, with no statistically significant difference between the proportions of correct answers given by any two grades of ophthalmologist. Although only a small number of ophthalmologists took part, it was thought that this group was representative of each training grade. Despite this being a pilot study and the limitations associated with this type of questionnaire, our findings suggest that the current system for training UK ophthalmologists in the area of low vision appears inadequate. There is little or no formal teaching on low vision and is only briefly mentioned in the curricula of basic specialist training $(\mathrm{BST})^{13}$ and higher specialist training $(\mathrm{HST})^{14}$ in ophthalmology from the Royal College of Ophthalmologists and the Royal College of Surgeons of Edinburgh.

It can be seen that the current registration system is still failing many, already disadvantaged, patients. Low vision must have a higher profile in the training of UK ophthalmologists if we are to make any inroads into the problem of under-registration of the vision impaired.

\section{Authors' affiliations \\ R J Barry, P I Murray, University of Birmingham, Birmingham, UK}

Correspondence to: Professor P I Murray, Academic Unit of Ophthalmology, Division of Immunity and Infection, University of Birmingham, Birmingham and Midland Eye Centre, Sandwell and West Birmingham Hospitals NHS Trust, City Hospital, Dudley Road, Birmingham B18 7QU, UK; p.i.murray@bham.ac.uk

Accepted for publication 3 December 2004

\section{REFERENCES}

1 Bruce IW, McKennel AC, Walker EC. Blind and partially sighted adults in Britain: the RNIB survey, Vol 1. London: HMSO, 1991.

2 Gibson JM, Lavery JR, Rosenthal AR. Blindness and partial sight in an elderly population. Br J Ophthalmol 1986:70:700-5.

3 Robinson R, Deutsch J, Jones HS, et al. Unrecognized and unregistered visual impairment. Br J Ophthalmol 1994;78:736-40.

4 Bunce C, Evans J, Fraser S, et al. BD8 certification of visually impaired people. Br J Ophthalmol 1998;82:72-6.

5 King AJW, Reddy A, Thompson JR, et al. The rates of blindness and partial sight registration in glaucoma patients. Eye 2000;14:613-19.

6 El-Hashimy MM, Aubert RE, Alich K, et al. Strategies to improve the reporting of legal blindness in Massachusetts. Am J Public Health 1997;87:425-8.

7 Greenblatt SL. Physicians and chronic impairment: a study of ophthalmologists interactions with visually impaired and blind patients. Soc Sci Med 1988;26:393-9.

8 Royal National Institute of the Blind. Benefits and concessions for registered blind and partially sighted people (April 2003).

9 National Statistics Online. Ethnicity and religion. www.statistics.gov.uk/ about/classifications/ns_ethnic_classification.asp (accessed 24 Oct 2003).

10 Aclimandos WA, Galloway NR. Blindness in the city of Nottingham (19801985). Eye 1988;2:431-4

11 Ritch $A E$, Ehtisham M, Guthrie $S$, et al. Ethnic influence on health and dependency of inner city residents. J R Coll Physicians Lond 1996;30:215-20. 12 Pardhan S, Mahomed I. The clinical characteristics of Asian and Caucasian patients on Bradford's low vision register. Eye 2002;16:572-6.

13 Curriculum of Basic Specialist Training in Ophthalmology, CB6/99. www.rcophth.ac.uk/edu_train/guides-curricular.html (accessed 9 Oct 2004). 14 Curriculum of Higher Specialist Training in Ophthalmology, $\mathrm{CHO} / 03$. www.rcophth.ac.uk/edu_train/guides-curricular.html (accessed 9 Oct 2004). 